\title{
Distance learning for students with hearing impairments in pandemic situation
}

\author{
S.T. Kokhan ${ }^{1}$, L.A. Osmuk ${ }^{2 *}$, and O.A. Varinova ${ }^{2}$ \\ ${ }^{1}$ Trans-Baikal State University, 672000, Chita, Russian \\ ${ }^{2}$ Novosibirsk State Technical University, 630102, Novosibirsk, Russia
}

\begin{abstract}
The article deals with the problem of organizing distance learning for Deaf students in a pandemic situation. This problem is evaluated differently by experts, many of whom speak of a complete failure. However, the description of how two Siberian universities, which have a relatively large number of students with hearing impairments, organized a remote format, allows us to talk about the possibility of more or less successful practices. The article presents empirical studies of the Trans-Baikal State University and Novosibirsk State Technical University, on the basis of which the analysis is carried out, the opinions of students, teachers and interpreters of the Russian sign language are compared. The results of the study prove that the system of distance education of the Deaf more satisfied the requests of Deaf students where sign language interpreter worked, who simultaneously carried out control and support. During the study, organizational problems were discovered. Solving the identified problems will allow us to build a more successful model, which will make it possible to prevent risks and find effective remote technologies for teaching the Deaf.
\end{abstract}

\section{Introduction}

In a few months of 2020, almost all educational institutions in the world were in educational chaos [1]. The forced disorder was accompanied by an uncomfortable environment and questionable ideas about how to remotely organize the educational process at the university. To a greater extent, these problems affected students with disabilities (sensory, physical, and somatic) [2]. Human Rights Watch called for additional measures to protect the rights of people with disabilities when responding to the pandemic [3]. Such measures include the organization of distance learning for students with disabilities of different nosological groups and, first of all, with hearing and visual impairments. The situation of the pandemic from the very beginning revealed the unpreparedness of most universities in terms of overcoming these problems, but they were gradually solved and now we can state the presence of individual experience of each educational organization. It is extremely useful to analyze the emerging practices of

\footnotetext{
*Corresponding author: osmuk@gmail.com
} 
distance learning for students with hearing impairments in universities that have a fairly large number of such students (for example, more than 25 students studying in different directions and courses).

Organizing the education of students with hearing impairments in inclusive groups remains an important task of universities, which has not been fully solved. The fact that the training of this category of students is problematic affects the persistence of the belief that it is better for the Deaf to receive education in special, rather than inclusive, groups or, perhaps, even special educational institutions (for example, Gallaudet University). The training of the Deaf requires, at a minimum, interpreter into Russian sign language, assistive equipment and psychological support. The situation of the pandemic, for all its suddenness, and the total introduction of distance learning have led to various kinds of difficulties. So, in addition to technical and organizational issues, there are complications that affect the ability of the brain of a Deaf student to receive, summarize and deposit all information during the transition from full-time offline to distance education [4]. Complications also arose with the emotional sphere of the Deaf students, since Russian sign language is the language of visual modality, the language of "eye contact", which requires direct communication. All this explains the large dropout rate of students with hearing impairments - too many of them were unable to consistently integrate into the educational process exclusively in a distance format.

The educational process involves active feedback, which in the case of distance learning continues to be carried out with the help of Russian sign language interpreter (accompanying texts and subtitles are not enough for online lectures, and, even more so, for seminars and practical classes). For a Deaf student, it is necessary not only to read, but also to understand the information. Education must be conducted using Russian sign language, because it is the native language for students with hearing impairments, and in accordance with the law on the Rights of Persons with Disabilities in the Russian Federation and other legal acts. In addition to the fact that the Deaf prefer a visual learning style, it is important that the information received in the classroom is embedded in the knowledge system. The latter requires both teachers and students to immerse themselves in the material, with teachers constantly monitoring its assimilation, which, consequently, makes a relevant assessment system necessray.

So, the rapid transition to distance learning for students with hearing impairments has led to a variety of problems in almost all universities around the world. Thus, during the pandemic, Malaysian students with hearing impairments complained about the poor quality of hearing aids, which hindered the assimilation of educational materials; in addition, the students' level of knowledge of computer technologies was insufficient, and a negative emotional state during online classes was noted [5]. In India, the transition to distance learning for the Deaf is complicated by the fact that Indian sign language, used for communication in everyday life, is poorly encouraged in educational institutions [2]. Apparently, distance learning negates the effect of inclusive education, since there is no direct communication of students with hearing impairments with classmates and teachers, and, as a result, the online format reduces the activity of special students and affects their academic performance [6].

Domestic specialists also responded to the remote format during the pandemic, and the first scientific reflection allowed us to focus on significant risks to the quality of education and, as a result, social injustice and tension [7]. For obvious reasons, the problems of quality and unfairness apply primarily to people with disabilities, including Deaf students. In this regard, it is possible to state in a certain sense the risk of social deprivation and increased social exclusion in relation to the Deaf group. It is no accident that Dmitry Alekseevskikh called what is happening "remote grief" [8]. And when the consequences of the pandemic became visible, there was a statement by the World Federation of the Deaf on 
accessible communication for Deaf and hard of hearing people during the COVID-19 pandemic [9] and a statement by the World Federation of the Deaf and the World Association of Sign Language Interpreters [10].

Thus, distance learning in its total format is likely to negatively affect the personal and professional development of a Deaf student. Taking place in the discourse of a tense, protracted pandemic situation, associated with an ongoing threat to health and a sense of fear, learning does not normally perform any of its functions. However, in the conditions of the modern information society and new requirements for professional training, distance technologies should be included in education. Therefore, it is appropriate to ask where distance learning is good and where, on the contrary, it is evil, and how ready we are for the next situation of a pandemic or any other situations that require long-term isolation of students. In the discourse of this article, the question is to what extent and how exactly distance learning should be organized in the designated situations for Deaf students.

\section{Materials and methods}

As an example, let's take the experience of two Siberian universities that can be fully classified as inclusive: Novosibirsk State Technical University (NSTU) and Trans-Baikal State University (TBSU). Both universities have strong centers of inclusive education, a fairly large number of students with disabilities (NSTU - 240, TBSU-87), and use distance learning technologies. Both universities have experience in teaching students with hearing impairments (NSTU-132, TBSU-22). In part, remote technologies were used in the educational process for students with disabilities. In early 2020, with the outbreak of the pandemic, both universities switched to distance learning using their own e-learning environment.

During the transition to distance learning, the teaching staff and students of universities faced a number of problems that affect the availability of education for students with disabilities. Thus, it turned out that not all teachers, especially older ones, have sufficient knowledge of computer technologies, and that distance learning required a significant amount of time to prepare more didactic material in a remote format, and to revise educational technologies. The most important thing was that interpreter Russian sign language had to be included in the remote process, while technically ensuring that the image was transmitted in good quality (sufficient to transmit the speed of hand movement during interpreter without loss of quality and without braking and "hanging up") on both sides - the interpreter and the student, prepare a video with subtitles, and rewrite the audio material into text. And, what is very important, to organize social and psychological support relevant to the conditions of distance learning in a pandemic situation.

In order to actually re-construct the educational process, it was necessary to solve the problems of all its participants, introduce them all into the virtual space and make it as comfortable as possible.

In order to minimize psychological and organizational problems during the introduction of the forced distance format (from spring 2020 to winter 2021), the states of all participants in the educational process were simultaneously analyzed in two universities using various empirical methods.

Thus, in the Trans-Baikal State University, a semi-structured, semi-formalized interview was conducted with students with hearing impairments $-\mathrm{n}=20$. In Novosibirsk State Technical University, a group interview was conducted with similar questions $-\mathrm{n}=50$, which made it possible to partially compare the results. University teachers $(n=20)$ and interpreter Russian sign language $(n=8)$ were also interviewed in-depth at Novosibirsk State Technical University post factum. The use of qualitative methods allowed not only to more accurately identify the problems that arise in students with hearing impairments and 
teachers/interpreter Russian sign language, but also to reveal the details of the subjective perception of the situation.

\section{Results}

The results obtained in the course of interviews at TBSU showed that almost all Deaf students, to one degree or another, know how to use a computer; out of 20 people $(n=20)$, only two have problems and feel insecure. As a rule, the reason for the lack of sufficient skills is the financial problems in the family, the inability to provide the child with normal equipment. But, from the students ' point of view, they studied hard and periodically turned to the teachers for help. However, distance learning has created enough problems and we can state too little satisfaction with the organization of training. According to the estimates of students with hearing impairments, about half of all the lectures that were held were not clear, even though the teachers tried to interest them and had presentations. For the Deaf, the presentations were uninformative and not clear to everyone (half of the respondents say this). At the same time, due to the fact that the teachers were loaded, and there were no ready-made, adapted for the Deaf, didactic materials and presentations, consulting and explaining the material was difficult. Despite the fact that the assessments were made in most cases on time, it is difficult to talk about an adequate assessment. Among the main difficulties faced by students, they named: adaptation to distance learning platforms and problems with Internet, an increased volume of tasks and the inability to build a stable schedule and daily routine, lack of communication with teachers and classmates.

In the semi-formal interview conducted with Deaf students of NSTU, different tools were used, however, some of the questions were identical, which allows us to compare the results in this part.

The study found that of the 50 Deaf students surveyed, 27 are satisfied that they have returned to full-time offline study, but 23 believe that distance learning is better; at the same time, those students who would like to stay in remote format, as a rule, began to lose motivation to learn and are more interested in relative freedom (fig. 1).

40 students noted that classes were held in all subjects regularly and, if there were any problems, then rarely. There were some students ( 6 people) who said that there were no classes or they were not conducted very systematically. Interestingly, of these six, two admit that they themselves missed classes. These results suggest that students are generally satisfied with the organization of classes, but apparently there were some problems (usually at the very beginning of the organization of the distance format). The conclusion is that, in general, it was possible to organize distance learning for the Deaf at some more or less satisfactory level, and even to build a dialogue between teachers/ administrators and students, but the developed system was not adjusted. The fact that, in general, distance learning took place is also evidenced by the answers to the question "Did you manage to master the electronic university system of distance learning and what were the problems?" Among the respondents, there were only 3 people who had major problems using the DiSpace program and this is due to the lack of computers and / or an Internet network, since some students are brought up in low-income families or live in remote areas. Similar results were obtained by TBSU researchers. 

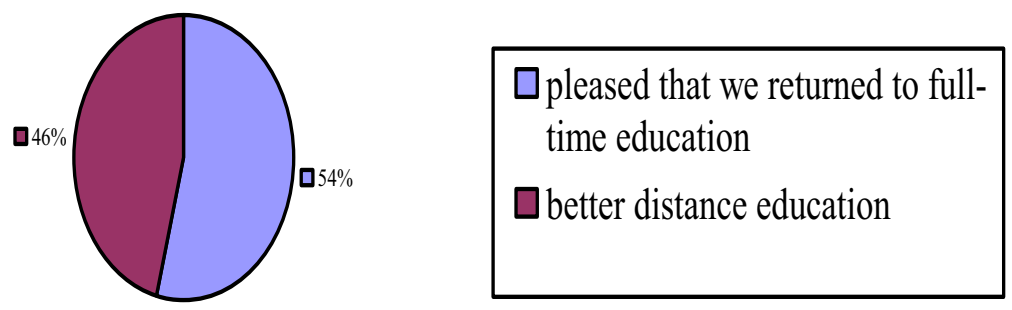

Fig. 1. Student survey results NSTU

Of course, the students admitted that they missed some webinars, but there were 17 people out of 50 who did not have any missed classes. As reasons, 11 people indicated that they did not understand all the material and/or were not interested in it. Apparently, here we should pay more attention to the teaching methods and to active forms of learning, which are extremely difficult to organize remotely. Computer game formats can be promising if they are used in a limited number, but they are not developed in the NSTU (with the exception of some elements). Most of the students admitted that they missed classes for personal reasons, someone went to rehearsals, someone went to the doctor, someone overslept, etc. In other words, such liberties in the distance format are more acceptable, which attracts students.

Remote classes at NSTU for Deaf students were conducted with the help of interpreters Russian sign language (RSL), but sometimes there were not enough interpreters (since the remote format required more effort and interpreters had to spend a lot of time accompanying the consultations) or the teachers themselves used more written material. Where there were no interpreters, they were very necessary for students, since most of them, accustomed to constant full-time support, even in the case of rare absence, would like to have such support all the time (fig. 2). It can be safely said that the normal organization of the educational process for the Deaf in the NSTU was only possible due to the presence of interpreters there (11 people in total).

In addition to doing their professional work, i.e. interpreters, interpreters RSL also monitor the assimilation of knowledge and the behavior of Deaf students. From this point of view, the opinion of the interpreter RSL on how the period passed with the transition to total distance learning is extremely important $(n=8)$. In a sense, they act as observers. The positive assessment of students after analyzing the opinions of interpreters is adjusted in some way. So, interpreters are more critical of attendance and believe that there were enough missed classes. But even if a little less than half of the students attended very well, the motivation to learn fell. It is important that the interpreters who monitored the Deaf students noted that the study was "not a priority" and the longer the period of forced distance learning lasted, the more relaxed the students became. 


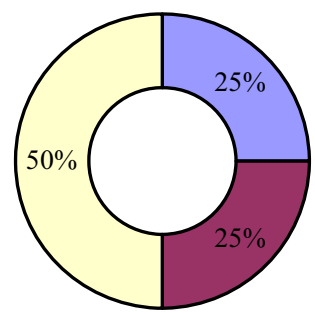
$\square$ translation of video lectures into Russian sign language
$\square$ translation of printed lectures into Russian sign language
$\square$ online consultations for Deaf students

Fig. 2. Interpreters RSL survey results NSTU

Questions concerning the distance format were also asked to teachers working with Deaf students. Since the teachers of NSTU have been teaching the Deaf for about 25 years, this gives the reason to think that they are well versed in the behavior of these special students. First of all, out of 20 teachers, only three see any advantages of the distance format (fig. 3).

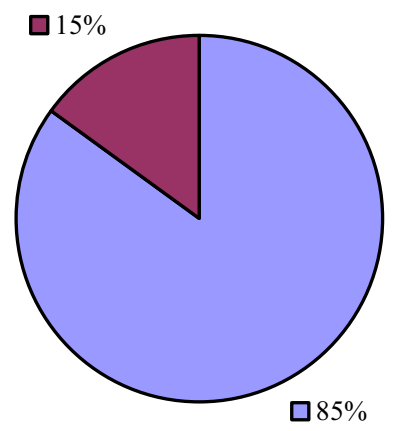
$\square$ pleased that we returned to full- time education
$\square$ better distance education

Fig. 3. Teachers survey results NSTU

As for attendance, most of the teachers are happy and believe that the students were quite responsible for the classes, but there were those who were lost at first, and did not show up until the end. In other words, the distance format assumes the personal responsibility of students, as for those who studied poorly, they quickly drop out of the process. The teachers noted the important function of interpreters Russian sign language, but said that new forms of work and some effective educational technologies were needed. In addition, the work of the Internet and the electronic system did not suit, problems arose constantly, which interfered with the stability of the educational process.

\section{Discussion}

Problems with university electronic systems and the poor orientation of Deaf students in educational websites affected the availability of higher education [11]. The identified barriers set out to improve the technological base of universities and to acquire technological skills from all persons with hearing impairment [12]. 
It became fully clear how difficult it is to understand the educational material without a interpreter RSL and the lack of subtitles when reading lectures by a teacher. Given that the training took place at home, Deaf students had a problem of constant extraneous distraction, and the educational material was not properly perceived [13]. Experts around the world came to similar conclusions. So, according to Webster, R., \& Blatchford, P. (2019) [14], an insufficient level of communication with a teacher in a pandemic situation led to low academic performance in students with hearing impairment. As a result, a high percentage of Deaf students expelled. The same is said by the NSTU and ZabSU: the percentage of those expelled here was twice as high as usual.

The results obtained made it possible to analyze the situation in Russian universities with distance learning for the Deaf in a pandemic situation. However, more attention was paid to the organization of the educational process and its evaluation. The psychological state of the Deaf is left somewhat aside here, while for the sake of completeness it must be taken into account. Nevertheless, the tools of both studies were based on a number of criteria and indicators that set a qualitative analysis of the situation and allow us to identify the most significant problems. The results obtained are also interesting because both Siberian universities (TBSU and NSTU) have a decent number of Deaf students and some experience of working with them.

The identified problems should primarily include the need for relevant educational technologies for teaching the Deaf in a remote format. NSTU was in a better position, because it has a whole professional group of interpreters Russian sign language, but even here the lack of educational technologies was very noticeable. It was difficult for the Deaf to master the material, it seemed less interesting than when it was explained in the offline format. That is why most of the Deaf students were happy to switch to offline education.

The fact that distance learning negatively affects the motivation and discipline of the Deaf has led to multiple expulsions. The offline format would allow us to retain students, since it is in this format that full-fledged support is possible.

Despite the obvious disadvantages of distance learning, there is a cautious opinion about the possibility of its partial use. However, today it is not clear exactly how it can be used. In addition, the results of the study showed that it is impossible to talk about the absolute failure of forced distance learning for the Deaf and about the so-called "remote grief". The problems found only emphasize that the situation is quite manageable, and there is a need not to forget that it can happen again.

\section{Conclusions}

The conducted analysis of the situation using the data of empirical studies of two inclusive universities is important in terms of developing a model of distance learning for the Deaf in the event of a pandemic. Modern society is a society of risks, and therefore, prevention can eliminate negative effects and make the educational process for the Deaf, if not comfortable, then better. Studies have identified problems, but at the same time, they have shown that the situation is not hopeless, it is manageable. Moreover, it can be considered that the pandemic has revealed problems that have occurred before, it has aggravated them, strongly raising the question of their solution. The tools developed by the research teams can also be used by other universities. In addition, the study can be continued with the use of other methods, in particular, when developing an educational model with elements of remote technologies adapted to the training of the Deaf, it would be possible to conduct a social experiment that would allow moving to more effective practices.

We can say that the accessibility test was applied to the inclusive educational space created by most universities. Probably, without their own electronic systems and support services, these universities would not have passed this test at all. 
The digital educational environment should be comfortable for all [15], including students with hearing impairment.

\section{References}

1. E.J. Sintema, Eurasia Journal of Mathematics, Science and Technology Education 16 (7), em1851. (2020). https://doi.org/10.29333/ejmste/7893, last accessed 2021/03/01.

2. U. Zeshan, Fan R. Huhua, J. Gillen, S. Panda, U. Papen, K.P. Tusting, J. Webster, Summary Report on "Literacy development with Deaf communities using sign language, peer tuition, and learner-generated online content: sustainable educational innovation" (University of Central Lancashire, Preston, 2016).

3. A. Nortajuddin, Facing a disability pandemic, ASEAN POST (Faced with a pandemic of people with disabilities, ASEAN POST), Retrieved from: https://theaseanpost.com/article/facing-pandemic-disabilities. (2020), last accessed 2021/03/03.

4. R. Rafidi, New Straits Times, https://www.nst.com.my/education/2020/05/590453/special-needs-students-facehurdles-elearning, last accessed 2021/03/06.

5. I.A. Krishnan, Mello Geraldine, Kok Shelen, Sabapathy Saabdev, Munian Saravanan, Sio Ching Hee, Kandasamy Pushpa, Ramalaingan Selvajothi, Baskaran Shasthrika, Kanan Vasudevan, Malaysian Journal of Social Sciences and Humanities (MJSSH) 106-116. (2020), https://doi.org10.47405/mjssh.v5i8.472, last accessed 2021/03/02.

6. R. Webster, P. Blatchford, European Journal of Special Needs Education 34 (1), 98-113. (2019).

7. D.A. Shtykhno, L.V. Konstantinova, N.N. Gagiev, Open education 24 (5), 72-81 (2020).

8. DISTANCE MOUNTAIN: a new format of education against Deaf children, https://voginfo.ru/education/2021/01/12/distancionnoe-gore-novyj-format-uchjobyprotiv-gluhih-detej/, last accessed 2021/03/06.

9. Statement on Accessible Communication for Deaf and Hard of Hearing People during COVID-19 Pandemic, http://wfdeaf.org/news/statement-on-accessible-communicationduring-c, ovid-19-pandemic/, last accessed 2021/03/03.

10. COVID-19 and Deafblindness Recommendations on inclusive policies from the global Deafblind community, https://wasli.org/cat_news, last accessed 2021/03/04.

11. C. Tandy, M. Meacham, Journal of Teaching in Social Work 29 (3), 313-328 (2009).

12. M. Debevc, P. Kosec, A. Holzinger, Multi-timed Tools Appl 54 (1), 181-199 (2011).

13. M. Pappas, E. Demertzi, Y. Papagerasimou, L. Koukianakis, D. Kouremenos, L. Loukidis, D. Athanasios, Education Sciences 8 (206), (2018).

14. R. Webster, P. Blatchford, European Journal of Special Needs Education 34 (1), 98113 (2019).

15. M.G. Sorokova, Psychological science and education 25 (2), 44-58 (2020). 